\title{
The psychiatrist as expert witness. Part 1: general principles and civil cases
}

\author{
Keith J. B. Rix
}

Abstract Expert witnesses have recently had a bad press but they have long played an important role in the administration of justice. This article begins by drawing attention to the guidance of the UK Academy of Medical Royal Colleges for medical expert witnesses and then sets out the latest guidance for experts in civil cases.

This is the first of two articles by Keith Rix that consider the role of the psychiatrist as expert witness. The second article, on criminal cases and the Royal College of Psychiatrists' guidance, will appear in the March issue of APT, together with an invited commentary by Sameer Sarkar on the topic.

The case of the eminent paediatrician Professor Sir Roy Meadow has focused intense media and public, as well as professional, attention on the role of the medical expert. Initially found guilty of serious professional misconduct by the General Medical Council, he was exonerated by the High Court, which found that, although his evidence was flawed it was honestly given. He did not intend to mislead the Court and his uncharacteristic and honest error fell far short of serious professional misconduct (General Medical Council v. Meadow [2006]).

This case has sent shock waves through the medical expert community and the reverberations continue. However, the courts have been assisted by medical experts since at least as early as 1345 , when surgeons were summoned to court to opine on the freshness of a wound (Rix, 2006). The courts have admitted psychiatric evidence since at least the 18th century, when Dr John Monro gave evidence at the trial of Lord Ferrers, who had shot his former steward in a fit of temper and pleaded insanity ( $R$ v. Ferrers).

One of the expert civil engineers in the 18thcentury Wells Harbour case, which helped establish the law on the admissibility of expert opinion by the UK courts, was threatened with an action for perjury because he got his tides going in the wrong direction (Rix, 2006). Experts will probably always be vulnerable to unmeritorious, scurrilous and vexatious complaints and in particular to complaints by aggrieved parties unwilling or unable to accept the expert's genuinely and honestly held opinion. Such complaints probably far exceed potentially meritorious complaints about flawed evidence and amply justify the view of the Master of the Rolls, Sir Anthony Clarke, in the Meadow case, that

'it should be possible to devise a scheme which reduces to an absolute minimum the risk of expert witnesses being vexed by unmeritorious complaints to regulatory bodies like the GMC' (General Medical Council v. Meadow [2006]).

Although the Meadow case has led some doctors, especially paediatricians, to be reluctant to become expert witnesses, it might be argued that this role is not so much a matter of choice but a matter of duty:

'It is a complaint made by coroners, magistrates and judges, that medical gentlemen are often reluctant in the performance of the offices, required from them as citizens qualified by professional knowledge, to aid the execution of public justice. These offices, it must be confessed, are generally painful, always inconvenient, and occasionally an interruption to business of a nature not to be easily appreciated or compensated' (Percival, 1803).

In 200 years little has changed. Today's expert witness is governed by various rules, protocols, codes and guidance, compliance with which will reduce but not eliminate the risk of complaint (Box 1). The purpose of this and my next article (Rix, 2008) is to bring these developments, and the work of the Royal College of Psychiatrists' Scoping Group on Court Work (Royal College of Psychiatrists, 2008), to the attention of psychiatrists, but my articles are no substitute for the original documents.

Keith Rix is a consultant forensic psychiatrist practising independently in London, Norfolk and West Yorkshire and at Cygnet Hospital, Wyke. He is based in West Yorkshire (The Grange, 92 Whitcliffe Road, Cleckheaton, BD19 3DR, UK. Email: drrix@the-grange.org.uk). He is a Fellow of the Expert Witness Institute and a Member of the Academy of Experts. He sits as Chairman of the General Medical Council's Fitness to Practise Panel. 


\section{Box 1 Recent guidance for expert witnesses}

2005 Medical Expert Witnesses: Guidance from the Academy of Medical Royal Colleges. Academy of Medical Royal Colleges (http://www.aomrc.org.uk/ documents/AoMRC_Experts1.pdf)

2005 Protocol for the Instruction of Experts to Give Evidence in Civil Claims. Civil Justice Council (http://www.justice. gov.uk/civil/procrules_fin/contents/ form_section_images/practice_ directions/pd35_pdf_eps/pd35_prot. pdf)

2006 Good Medical Practice. General Medical Council (http://www.gmc-uk.org/ guidance/good_medical_practice/ index.asp)

2006 Disclosure: Experts' Evidence and Unused Material. Guidance Booklet for Experts. Crown Prosecution Service (http:// www.cps.gov.uk/publications/docs/ experts_guidance_booklet.pdf)

2006 Guidance on the use of experts in criminal trials. $R$ v. Bowman [2006]

2006 Criminal Procedure Rules, Part 33: Expert Evidence (http://www.justice.gov.uk/ criminal/procrules_fin/contents / rules/part_33.htm)

\section{Guidance from the Academy of Medical Royal Colleges}

The Academy of Medical Royal Colleges endorses the professional conduct principles set out in paragraphs 63-67 of the General Medical Council's Good Medical Practice (Box 2). To fulfil these principles, the Academy recommends that medical expert witnesses should ensure that their statements, reports and verbal evidence are:

- straightfoward (not intentionally misleading or biased)

- as objective as possible and do not omit any material or information that does not support the opinion expressed or conclusions reached

- properly and fully researched.

Furthermore, they should be presented with 'the appropriate professional demeanour' (Academy of Medical Royal Colleges, 2005).

\section{Box 2 Good medical practice in writing} reports

- 'You must be honest and trustworthy when writing reports...'

- 'You must do your best to make sure that any documents you write or sign are not false or misleading. This means that you must take reasonable steps to verify the information in the documents, and that you must not deliberately leave out relevant information.'

- 'If you have agreed to prepare a report, complete or sign a document or provide evidence, you must do so without unreasonable delay.'

- 'If you are asked to give evidence or act as a witness in litigation or formal enquiries, you must be honest in all your spoken and written statements. You must make clear the limits of your knowledge or competence.'

(General Medical Council, 2006: paras 63, 65-67)

This guidance was prompted in part by a report on sudden unexpected death in infancy (Royal College of Pathologists \& Royal College of Paediatrics and Child Health, 2004). This report contains a number of questions that a court ought to have answered before accepting a doctor as an expert witness (Box 3). It also sets out the roles of the medical Royal Colleges and specialty faculties with regard to expert witnesses. These include ensuring that doctors have appropriate opportunities to train as medical expert witnesses and that they clearly understand the responsibilities and duties of the role. Such an understanding might best be obtained through CPDapproved courses.

Box 3 Questions that a court ought to have answered before accepting a doctor as an expert witness

- When did the doctor last see a case (like this) in their own clinical practice?

- Is the doctor in good standing with their medical Royal College?

- Is the doctor up to date with CPD?

- Has the doctor received training in the role of an expert witness in the past 5 years?

(Royal College of Pathologists \& Royal College of Paediatrics and Child Health, 2004) 


\section{Protocol for the Instruction of Experts to give Evidence in Civil Claims}

This protocol, produced by the Civil Justice Council (2005), is intended to guide experts in the interpretation of and compliance with Part 35 of the Civil Procedure Rules and its associated Practice Direction (Rix, 2000).

The protocol includes a useful test of independence: the expert would express the same opinion if given the same instructions by an opposing party.

Penalties can be imposed if an expert has not complied with the Civil Procedure Rules. For example, in the case of Phillips v. Symes [2004] the court made a costs order against a consultant psychiatrist acting as an expert witness, who, by his evidence, caused significant expense to be incurred and did so in breach of his duties under Part 35 of the Civil Procedure Rules and thereby in flagrant disregard of his duties to the court.

Those instructing the expert are required to ascertain the expert's availability to attend the trial before the trial dates are fixed but there is a reciprocal obligation on the part of experts to ensure that those instructing them are always aware of dates to be avoided. Compliance with these guidelines should reduce the risk that experts will be called to attend

Box 4 Terms of appointment to be agreed at the outset in a civil case

- The capacity in which the expert is to be appointed (e.g. party-appointed expert, single joint expert or expert advisor)

- The services required of the expert (e.g. provision of expert's report, answering questions in writing, attendance at meetings, attendance at court)

- Time for delivery of the report

- The basis of the expert's charges (either daily or hourly rates and an estimate of the time likely to be required, or a total fee)

- Travelling expenses and disbursements

- Cancellation charges

- Any fees for attending court

- Time for making the payment

- Whether fees are to be paid by a third party

- If a party is publicly funded, whether or not the expert's charges will be subject to assessment by a costs officer

Civil Justice Council (2005)

\section{Box 5 Expert witness organisations}

- Academy of Experts http:/ / www.academy-experts.org

- Expert Witness Institute http:/ / www.ewi.org.uk

- Society of Expert Witnesses http:/ / www.sew.org.uk

court when they are on holiday or have important clinical or academic commitments.

Medical experts have been reluctant and slow to adopt business practices such as drawing up terms of appointment or terms and conditions of service before agreeing to undertake to provide expert opinions. The protocol states that certain terms (Box 4) should be agreed at the outset. These points should be set out in writing - model forms for this purpose can be obtained from expert witness organisations (Box 5).

The protocol offers a helpful list of information that should be supplied to the expert on instruction. This includes obvious information such as the telephone number of the person on whom the report is being prepared and, sensibly, a timetable for the completion and delivery of each stage of the expert's work. It is incumbent on the expert to request clarification if they do not receive clear instructions.

The procedure is set out for asking the court for directions, and there is guidance on how an expert might withdraw from a case and the reasons for doing so.

The protocol draws attention to the model forms of experts' reports produced by the Academy of Experts and the Expert Witness Institute (see also Rix, 1999b). Model reports, one on a criminal case and one on a civil case, based on such forms, are available from my website (http: / / www.drkeithrix.co.uk).

Experts' reports in civil proceedings must be verified using the 'statement of truth' (Box 6).

Box 6 Statement of truth for reports in civil cases

'I confirm that insofar as the facts stated in my report are within my own knowledge I have made clear which they are and I believe them to be true, and the opinions I have expressed represent my true and complete professional opinion.'

Civil Justice Council (2005) 
Experts are required to keep questions of fact and opinion separate and, in relation to facts, to distinguish clearly between those that the expert knows to be true and those that are assumed to be true. For the psychiatrist, it may be appropriate in most cases to indicate that, unless otherwise indicated, all facts are assumed facts apart from the psychiatrist's findings on examination and the results of tests or investigations.

A 'summary of conclusions' is mandatory at the end of the report.

Contrary to the belief of many experts, there is no requirement that the letter of instruction should be appended to the report. Indeed, it is privileged. However, the statement of the substance of all material instructions, including any oral instructions, is mandatory. The omission of 'off the record' oral instructions is not permitted. If there are reasonable grounds to believe that the statement is inaccurate or incomplete, the expert may be cross-examined on it.

There are requirements for experts to be informed whether and, if so, when their reports have been disclosed and to be given the opportunity to comment on other reports in their area of expertise at the earliest opportunity. This should avoid experts being unable to read other experts' reports until just before the trial.

The protocol also has a helpful section on the amendment of reports.

The protocol seems to be inconsistent with regard to discussions (permitted by telephone, email, letter or face to face) between experts. It states that one of the purposes of such discussions is to identify issues on which they agree and disagree and summarise reasons for disagreement. However, it subsequently says that the expert's statement should include 'a list of issues that have been agreed, including, in each instance, the basis of agreement'. It should seldom be necessary to know why certain matters are agreed and it seems that compliance with this requirement will add unnecessarily to the time and cost of the litigation.

The production of an agenda, usually by the parties' solicitors, but with cooperation from the experts, appears now to be the rule rather than the exception.

\section{Recent judgments}

Three recent cases involving expert evidence, two civil and one criminal, have implications for expert witnesses in general.

\section{Conflict of interest}

In a case involving an unsuccessful claim for damages for nervous shock and psychiatric injury allegedly caused by negligent medical treatment (Toth v. Jarman [2006]), the claimant sought to have the dismissal of his claim set aside on the grounds that the defendant's expert had not disclosed a conflict of interest. The claimant failed on other grounds but the Court of Appeal took the opportunity to set out important points of principle and practice. As a matter of principle it was held that the presence of a conflict of interest does not automatically disqualify an expert because the key question is whether or not the expert's opinion is independent. As a matter of practice the Court was of the view that the Civil Procedure Rules Committee should give consideration to requiring experts to declare at the end of their reports:

(i) that they have no conflict of interest of any kind, other than any that they have disclosed in the report;

(ii) that they did not consider that any interest that they had disclosed affected their suitability as an expert on any issue on which they had given evidence;

(iii) that they would advise the party by whom they had been instructed if, between the date of their report and the trial, there was any change in their circumstances that affected their answers to (i) and (ii) above.

\section{Stating the basis of an opinion}

The criminal case of $R v$. Puaca [2005] concerned a man convicted of the murder of his partner. In this case a pathologist who gave evidence that the partner had been suffocated was criticised on the basis that he had failed to draw attention to the lack of any pathological evidence for suffocation. Mr Puaca's conviction for murder was quashed. It was agreed that suffocation was a possibility but, as such, that this was mere hypothesis. Experts must identify the evidence on which their opinion is based and, if advancing an hypothesis for which there is no evidence, must explain that what is being advanced is an hypothesis and, if it is controversial, explain that this is so.

\section{General duties}

The duties and responsibilities of expert witnesses in civil cases are well presented in a commercial case relating to the sinking of a merchant shipping vessel, the Ikarian Reefer (National Justice Compania Naviera SA v. Prudential Assurance C Ltd [1993]). I have discussed this guidance in a previous article in this journal (Rix, 1999a) and my next article (Rix, 2008) will describe its incorporation into new rules for experts reporting in criminal cases. 


\section{Declaration of interest}

None.

\section{References}

Academy of Medical Royal Colleges (2005) Medical Expert Witnesses. Guidance from the Academy of Medical Royal Colleges. AMRC.

Civil Justice Council (2005) Protocol for Instructions of Experts to Give Evidence in Civil Claims.

General Medical Council (2006) Good Medical Practice. GMC.

Percival T. (1803) Medical Ethics or a Code of Institutes and Precepts Adapted to the Professional Conduct of Physicians and Surgeons. S. Russell.

Rix, K. J. B. (1999a) Expert evidence and the courts: 1. The history of expert evidence. Advances in Psychiatric Treatment, 5, 71-77.

Rix, K. J. B. (1999b) Expert evidence and the courts. 2. Proposals for reform, the expert witness bodies and 'the model report'. Advances in Psychiatric Treatment, 5, 154-160.

Rix, K. J. B. (2000) The new Civil Procedure Rules: 2. Part 35 provisions and their implications. Advances in Psychiatric Treatment, 6, 219-225.

Rix, K. J. B. (2006) England's first expert witness? The Expert and Dispute Resolver, 11(2), 6-18.

Rix, K. J. B. (2008) The psychiatrist as expert witness: criminal cases and Royal College of Psychiatrists' guidance. Advances in Psychiatric Treatment, in press.

Royal College of Pathologists \& Royal College of Paediatrics and Child Health (2004) Sudden Unexpected Death in Infancy: A Multi-agency Protocol for Care and Investigation. RCPath \& $\mathrm{RCPCH}$.

Royal College of Psychiatrists (2008) Court Work: Final Report of a Scoping Group (College Report CR147). Royal College of Psychiatrists. In press.

General Medical Council v. Meadow [2006] EWCA Civ 1390.

National Justice Compania Naviera SA v. Prudential Assurance C Ltd [1993] 2 Lloyds Rep 68.

Phillips v. Symes [2004] EWHC 2330 (Ch).

$R$ v. Bowman [2006] EWCA Crim 417.

$R$ v. Ferrers 19 State Trials 886.

$R$ v. Harris and others [2006] 1 Cr App R 5.

$R$ v. Puaca [2005] EWCA Crim 3001.

Toth v. Jarman [2006] EWCA Civ 1028.

\section{MCQs}

1 Guidance from the Academy of Medical Royal Colleges for medical expert witnesses:

$\mathrm{d}$ was prompted by the GMC finding in the Meadow case

e suggests that they should receive training in the role of an expert witness every 10 years

$f$ endorses guidance in the GMC's Good Medical Practice

$\mathrm{g}$ is not concerned with the demeanour of the expert in court

$\mathrm{h}$ is limited to the role of medical experts in civil litigation.

2 The Protocol for the Instruction of Experts to give Evidence in Civil Cases:

a leaves unanswered how the expert can test the independence of his or her opinion b gives as an example the power of the court to make a costs order against a psychiatrist

c requires experts to append to their report a copy of their letter of instruction

d does not apply to 'off the record' discussions between experts and instructing solicitors

e prohibits experts discussions by email.

3 Medical experts:

a had no place in the court process until Dr John Monro gave evidence in the murder trial of Lord Ferrers

$b$ in the early 19th century had a reputation for the eagerness with which they fulfilled their public office

c will not be questioned as to whether or not they are up to date with CPD

d should advise those instructing them of dates to be avoided when convening conferences or listing trials

e instructed in civil cases do not need to agree the terms of their appointment or their terms and conditions of service at the outset of the case.

\section{Expert reports}

a in civil cases have to be verified by a statement of truth

b are not covered by the GMC's Good Medical Practice

c in civil cases should have a summary of conclusions at the beginning of the report

d do not need to include material or information that does not support the opinion expressed or conclusions reached

e must conform to the model form produced by the Academy of Experts and the Expert Witness Institute.

5 According to recent judgments:

a a conflict of interest does not automatically disqualify an expert from giving an opinion in a case

b guidance is likely to be issued to the effect that experts should disclose any conflict of interest in the covering letter sent with their report

c if, as a result of a change in circumstances, an expert identifies a conflict of interest, the expert must advise the court immediately

$\mathrm{d}$ an expert may not give evidence based on hypothesis

e application of guidance on expert evidence established in the Ikarian Reefer case is to be limited to civil cases.

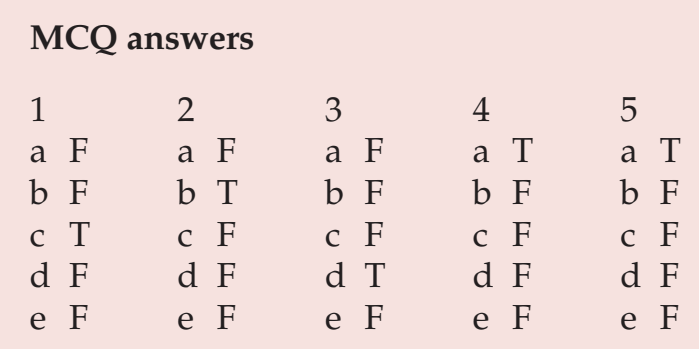

